\title{
EDITORIAL
}

Versão original

DOI: http://dx.doi.org/10.1590/Soo34-759020190501

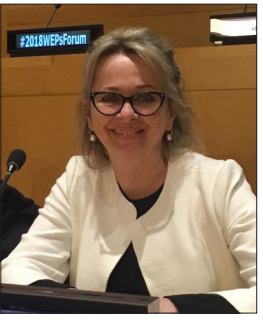

MARIA JOSÉ TONELLI Editora-chefe

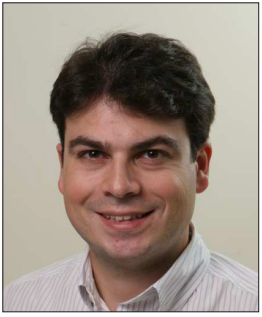

FELIPE ZAMBALDI Editor-adjunto

\section{BINARISMOS E AFINS}

A próxima conferência do Academy of Management, a ser realizada em 2020, em Vancouver, Canadá, terá como tema "Broadening our sight", ou "Ampliando nossa visão" (Aguinis, 2019). Nada mais apropriado para os tempos atuais. Em vez de lamentar porque a Academia em Administração nem sempre tem o mesmo prestígio de outras áreas (tema já bem estudado por Khurana, 2007), a chamada de trabalho propõe que os pesquisadores abandonem posições de soma zero presente nas dicotomias que cercam as pesquisas em Administração (por exemplo: pesquisas qualitativas ou quantitativas? Pesquisas sobre o nível micro, meso ou macro?) e busquem contribuições que ultrapassem esse modelo binário, pouco útil para a construção de sinergias na busca por soluções de problemas. Mas não se trata apenas de problemas internos às organizações. Os problemas externos estão, definitivamente, associados à gestão, como estratégias políticas, Supply chain e gestão de pessoas, ou formas de liderança, entre tantos outros temas que estudamos em Administração. Posições polarizadas não contribuem para a solução criativa de problemas (mas a diversidade e o pluralismo, sim), e a complexidade do cenário contemporâneo exige respostas que interseccionem diversas áreas de conhecimento. A área de Administração precisa conciliar as dificuldades internas enfrentadas pelas empresas com as questões políticas e sociais que as cercam.

Parece que estamos sempre batendo na mesma tecla em nossos editoriais, pois já tratamos aqui da necessidade de uma ciência responsável (Tonelli \& Zambaldi, 2018a), que ultrapasse dicotomias (Tonelli \& Zambaldi, 2016, 2018b) e que tenha utilidade para um mundo sustentável. Mas as últimas edições do Academy of Management também estão batendo nessa mesma tecla: em 2019, o tema da conferência foi "Understanding inclusive organizations"; em 2018, "Improving lives"; em 2017, "At the interface" ("Entre sistemas e humanos"), apenas para citar as preocupações da Associação nestes últimos anos. A inquietação com a produção de conhecimento para um mundo melhor nunca esteve tão premente, seja no Global North ou no Global South.

Os artigos desta edição contribuem para esse debate: "Humor como catalisador e neutralizador da eficácia da liderança”, de Filipe Sobral, Liliane Furtado e Gazi Islam, trata do impacto do humor presente na liderança de estagiários, mas poderia perfeitamente ser ampliado para outros profissionais nas organizações. 0 artigo “Felicidade no trabalho: Validação de uma escala de medição”, de Carolina Ramirez-Garcia, Juan Garcia-Alvarez de Perea e Julio Garcia-Del Junco, trata da importância da medição da felicidade no trabalho para a eficiência dos trabalhadores; nestes tempos de questionamentos sobre o futuro do trabalho, o tema da felicidade é mais do que apropriado: será que é mesmo possível ser feliz no trabalho hoje ou no futuro? De qual trabalho se trata? Trazendo uma luz sobre o afastamento da produção acadêmica das necessidades imediatas da sociedade, 0 artigo de Anielson Barbosa da Silva discute o "Produtivismo acadêmico multinível: Mercadoria performativa na pós-graduação em Administração”. Finalmente, o artigo de Andre Ofenhejm Mascarenhas e Allan Claudius Queiroz Barbosa, "Gestão de recursos humanos sustentável e responsabilidade socioambiental: Uma agenda para debates", também trata de questões atuais e pertinentes, enfatizando a importância de a área de Recursos Humanos adotar uma agenda de responsabilidade socioambiental.

Completa esta edição a Pensata de autoria de Leticia Moreira Casotti, “Ensino e pesquisa em Marketing: A pílula vermelha como alternativa”, em que mostra a dicotomia que cerca a área. E, na seção Indicações Bibliográficas, a professora Claudia Affonso Silva Araujo traz cinco livros sobre gestão de serviços de saúde.

Boa leitura!

Maria José Tonelli1 | ORCID: 0000-0002-6585-1493

Felipe Zambaldi ${ }^{1}$ | ORCID: 0000-0002-5378-6444

${ }^{1}$ Fundação Getulio Vargas, Escola de Administração de Empresas de São Paulo, São Paulo, SP, Brasil

\section{REFERÊNCIAS}

Aguinis, H. (2019). AOM 2020 Theme - 20/20: Broadening our sight. In: 8oth Annual Meeting of the Academy of Management, Vancouver, BC. Recuperado de http://aom.org/annualmeeting/theme

Khurana, R. (2007). From higher aims to hired hands: The social transformation of American business schools and the unfulfilled promise of management as a profession. Princeton, NJ: Princeton University Press.
Tonelli, M. J., \& Zambaldi, F. (2016). Academia e prática. RAE-Revista de Administração de Empresas, 56(4), 374. doi:10.1590/So034-759020160401

Tonelli, M. J., \& Zambaldi, F. (2018a). Ciência responsável e impacto social da pesquisa em Administração. RAE-Revista de Administração de Empresas, 58(3), 215-216. doi:10.1590/ s0034-759020180301

Tonelli, M. J., \& Zambaldi, F. (2018b). Pesquisas qualitativas, pesquisas quantitativas e além. RAE-Revista de Administração de Empresas, 58(5), 449-450. doi:10.1590/So034759020180501 